\title{
An Effective Wind Speed Observer for Pitch Fault Detection in Wind Turbines
}

\author{
Y. Vidal ${ }^{1}$, C. Cárdenas ${ }^{2}$, L. Acho ${ }^{1}$ and L. Gorostiaga ${ }^{2}$ \\ ${ }^{1}$ Universitat Politècnica de Catalunya, \\ Applied Mathematics-III (MA-3) Department, CoDAlab, \\ Comte d'Urgell, 187, 08036, Barcelona, Spain.
}

Phone number:+0034934137309, e-mail: yolanda.vidal@upc.edu, leonardo.acho@upc.edu

${ }^{2}$ Centro Tecnológico CARTIF

Parque Tecnológico de Boecillo, 205, 47151, Valladolid, Spain.

Phone number:+0034983546504, e-mail: clecar@cartif.es, lazgor@cartif.es

\begin{abstract}
This paper presents a methodology to design an effective wind speed observer using an alternative mathematical representation of the aerodynamic torque of a variable-speed wind turbine. This alternative model is linear in parameters. Then, using this observer, a pitch fault detection scheme is conceived. Numerical experiments using the National Renewable Energy Laboratory wind turbine simulator FAST (Fatigue, Aerodynamics, Structures, and Turbulence) code were performed to support the design.
\end{abstract}

\section{Key words}

Observer, fault detection, wind turbine, variable-speed, FAST.

\section{Introduction}

Due to the recent innovations in mechatronics systems, wind energy is an important, accessible energy source that is available in almost all parts of the world via wind turbine (WT) machines ([1], [2], and [3]). Today, this technology contributes to a large part of the world's power production [4]. One way to ensure the reliability and robustness of a WT system is by designing fault detection systems, particularly for the rotational structure of WTs [3]. Furthermore, fault detection systems can be used to establish new trends in strategies and techniques to improve the overall performance of WT systems [3] and to reduce the cost of operation and maintenance [5]. According to [5], the highest failure frequency and cause of the largest percentage of downtime occurs during the control system stages. In this paper, we are interested in detecting pitch actuator faults of a controlled wind turbine because these types of faults affect the rotational structure of a WT. Obviously, other sources of faults also exist ([4] and [5]).

Wind speed estimation is an important issue in fault detection systems, modeling, and control design of WTs (see [5], [6], [7], [8] and the references therein). For modeling and aerodynamic analysis, wind speed information can be obtained using anemometers. However, this information is not efficient when estimating the wind speed on WT blades
[1], [6], [9]. The rotator of the wind turbine is subject to a spatially and temporally distributed wind field; the wind speed varies significantly at different points over the blades plane. In fact, there is no such thing as the "wind speed" experienced by a wind turbine; it may be considered to experience an effective wind speed which is the average speed over the blades that produce the same aerodynamic torque [10]. A direct measurement of effective wind speed is impossible [11], [12]. So far, many of the effective wind speed observer designs reported are based on the Kalman filter approach [7]. However, an interesting observer approach using the immersion theory is presented in [8]. This theory is based on deterministic systems. According to [8], the primary difficulty of wind speed observer design is the nonlinear effect of the wind on the rotor dynamics.

One contribution of this paper is the design of an effective wind speed observer based on an alternative model (linear in parameters) of the aerodynamic torque. Once the wind speed observer is obtained and given a controlled WT operating in the partial load region, a pitch fault detection system can be created in a straight forward manner following a similar design as given in [13] for fault detection in base isolation devices.

This paper is organized as follows. In Section 2 the basic mathematical model of a WT is recalled and then an alternative model is proposed. Also in this section the FAST WT model (which will be used for numerical simulations) is explained. Section 3 presents the torque and pitch control laws used. In Section 4 the effective wind speed observer is stated. In Section 5, the fault detection system is proposed and validated through numerical simulations with FAST. Section 6 states the conclusions. 


\section{WT models}

\section{A. Standard WT model}

A basic mathematical model of a WT is given by [1], [8], and [14]:

$$
J_{t} \dot{w}_{r}=T_{a}-\tau_{c}
$$

where $J_{t}$ is the turbine total inertia, $w_{r}$ is the rotor speed, $T_{a}$ is the aerodynamic torque due to the wind effect on the blades, and $\tau_{c}$ is the generator torque (control input) (see Figure 1).

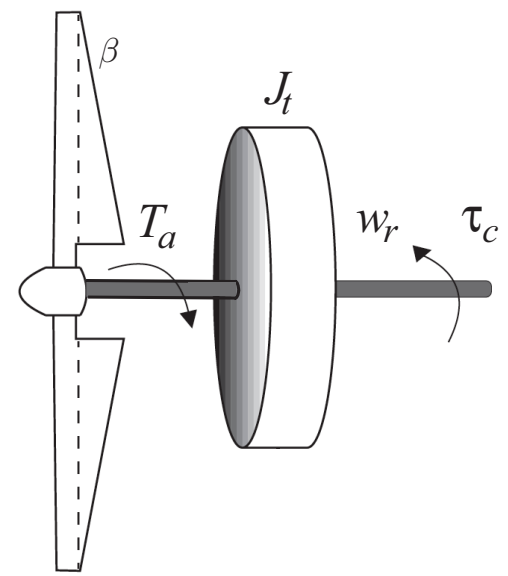

Fig. 1. One mass model of a WT.

The aerodynamic torque is given by

$$
T_{a}=\frac{1}{2} C_{q}(\lambda, \beta) \rho \pi R^{3} u^{2},
$$

where $\rho$ is the air density, $R$ is the turbine radius, $u$ is the wind speed, $\beta$ is the pitch angle, and

$$
\lambda=\frac{R w_{r}}{u}
$$

is the tip-speed ratio. We assume that the blades are controlled collectively and hence, have the same pitch angles. For different pitch angles, the aerodynamic torque can be slightly modified (see [5]). Finally, $C_{q}(\cdot, \cdot)$ is given by

$$
C_{q}(\lambda, \beta)=\frac{C_{p}(\lambda, \beta)}{\lambda}
$$

where $C_{p}(\cdot, \cdot)$ is the power coefficient that depends on the geometry of the WT, among other parameters, and is highly nonlinear. Typically, this function can be estimated experimentally, for example, in a wind tunnel where the wind speed is known [8].

\section{B. Alternative WT model}

To obtain a wind observer system, we propose the following alternative WT model:

$$
\dot{w}_{r}=\frac{\alpha_{1} u}{w_{r}}+\alpha_{2} \beta-\frac{\tau_{c}}{J_{t}} .
$$

That is, we choose the aerodynamic torque to be represented by

$$
T_{a}:=\left(\frac{\alpha_{1} u}{w_{r}}+\alpha_{2} \beta\right) J_{t},
$$

though other possibilities exist [16]. The parameters $\alpha_{1}$ and $\alpha_{2}$ will be identified in Section 4 .

\section{FAST WT model}

The FAST code [17] is a comprehensive aeroelastic simulator capable of predicting the extreme and fatigue loads of twoand three-bladed HAWTs. This simulator was evaluated in 2005 by Germanischer Lloyd WindEnergie and found suitable for the calculation of onshore wind turbine loads for design and certification [15]. See [17] for further details. Numerical simulations with FAST on Matlab-Simulink were performed with the NREL WP 1.5-MW wind turbine. The wind turbine characteristics are summarized in Table I.

TABLE I

WT CHARACTERISTICS.

\begin{tabular}{lc}
\hline Number of blades & 3 \\
Height of tower & $82.39 \mathrm{~m}$ \\
Rotor diameter & $70 \mathrm{~m}$ \\
Rated power & $1.5 \mathrm{MW}$ \\
Gearbox ratio & 87.965 \\
Nominal rotor speed $\left(w_{n}\right)$ & $20 \mathrm{rpm}$ \\
\hline
\end{tabular}

The wind inflow for the simulations is shown in Figure 2. This wind inflow reaches wind speeds that are above the rated power operating conditions. From Figure 2, the rated wind speed for the wind turbine is $11.8 \mathrm{~m} / \mathrm{s}$, which coincides with the mean wind speed profile. This wind inflow is nonstationary and is given by FAST.

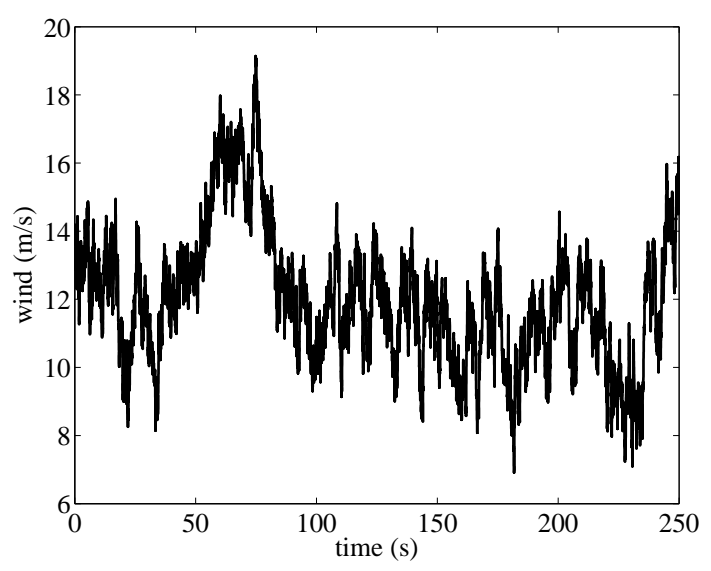

Fig. 2. Wind speed profile.

\section{Control laws}

\section{A. Torque Controller}

In this work, the dynamic chattering torque control for power regulation stated in [14] is used:

$$
\dot{\tau_{c}}=\frac{-1}{w_{g}}\left[\tau_{c}\left(a w_{g}+\dot{w}_{g}\right)-a P_{\text {ref }}+K_{\alpha} \operatorname{sgn}\left(P_{\mathrm{e}}-P_{\text {ref }}\right)\right] .
$$


where $w_{g}$ is the generator speed, $P_{\mathrm{e}}$ is the electrical power, $P_{\text {ref }}$ is the reference power, and $a$ and $K_{\alpha}$ are positive parameters. The control objective is that the electrical powertracking error given by

$$
e=P_{\mathrm{e}}-P_{\text {ref }},
$$

tends to zero. It has been proven that the controller ensures finite time stability [18], [14]. Moreover, it does not require information from the turbine total external damping or the turbine total inertia. This control only requires the generator speed and electrical power of the WT. In the numerical experiments with FAST the parameter values $a=1$ and $K_{\alpha}=10^{5}$ are used.

\section{B. Pitch Controller}

To assist the torque controller with regulating the wind turbine electric power output, while avoiding significant loads and maintaining the rotor speed within acceptable limits, a pitch proportional derivative (PD) controller is added to the rotor speed tracking error:

$$
\beta=K_{p}\left(w_{r}-w_{n}\right)+K_{d} \dot{w}_{r}, \quad K_{p}>0, K_{d}>0
$$

where $w_{r}$ is the rotor speed and $w_{n}$ is the nominal rotor speed, at which the rated electrical power of the wind turbine is obtained.

In the numerical experiments with FAST the parameter values $K_{p}=0.3$ and $K_{d}=0.1$ are used.

\section{Effective wind speed observer}

Using the parametric identification method stated in [20], and the first 50 seconds of the given wind speed (Figure 2), we estimate the parameters in equation 5 as $\alpha_{1}=1.85$ and $\alpha_{2}=-0.1$.

An effective wind speed estimation, $\hat{u}$, can be easily obtained from (5) by solving in terms of $u$ :

$$
\hat{u}=\frac{\left(\dot{w}_{r}-\alpha_{2} \beta+\tau_{c} / J_{t}\right) w_{r}}{\alpha_{1}} .
$$

A difficulty with this system (7) is its dependence on $\dot{w}_{r}$, which is usually unknown. We overcome this difficulty using the following semi differentiator equation ([21], page 304):

$$
\begin{aligned}
\dot{x}_{1} & =\frac{w_{r}-x_{1}}{\tau}, \\
x_{1}(0) & =w_{n} .
\end{aligned}
$$

where the time constant $\tau$ is small and $\dot{x}_{1}$ is an approximation of $\dot{w}_{r}$. Then, our wind speed observer yields

$$
\hat{u}=\frac{\left(\dot{x}_{1}-\alpha_{2} \beta+\tau_{c} / J_{t}\right) w_{r}}{\alpha_{1}},
$$

Let us set $\tau=0.01$. To evaluate the performance of the proposed observer, let us use the FAST simulator with the previously given data. Figure 3 shows the corresponding numeric experimental results. The estimated effective wind speed is useful for fault detection purposes as is shown in the next section.

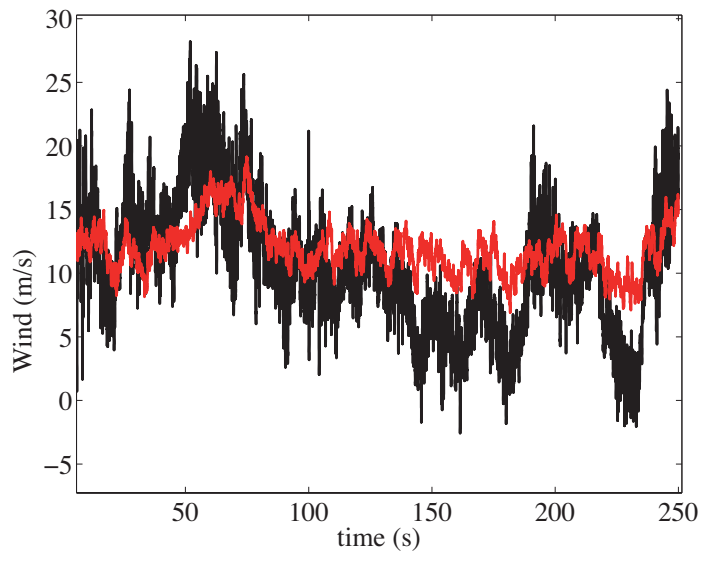

Fig. 3. Simulation results: red line represents the true wind speed, and the black line is its estimation.

\section{Pitch fault detection system}

The pitch system response depends on the backlash in the pitch actuator and bearings. In this work, the studied fault is an increase in the backlash. The amount of side-to-side play in the system is referred to as the deadband. As it is shown in Figure 4, $\beta$ is the real pitch angle whereas $\beta_{r}$ is the reference pitch. The backlash has been simulated with Simulink's backlash diagram block. The pitch actuator is modeled in FAST as a second-order system.

Let us propose the following system:

$$
\dot{w}_{h}=\frac{\alpha_{1} \hat{u}}{w_{r}}+\alpha_{2} \beta_{r}-\frac{\tau_{c}}{J_{t}}-\alpha\left(w_{h}-w_{r}\right) .
$$

This system is a type of observer that can be used to detect faults during the pitch control stage. The stability of the system is easily proven by defining $e(t)=w_{h}-w_{r}$. Then, $\dot{e}=-\alpha e$ if the WT model is represented by our alternative model (with $u(t)=\hat{u}(t)$ and $\beta_{r}=\beta$ ).

Now, let us use the following residual dynamic system:

$$
\dot{x}_{f}=0.1\left(-x_{f}+\left|w_{r}(t)-w_{h}(t)\right|\right) .
$$

The pitch fault was simulated as follows: from time 0 to 100 seconds the deadband is set equal to 0.05 and from time 100 to 250 seconds the deadband value is changed to 0.1 simulating a fault. According to Figure 5, the residual signal clearly detects the fault.

We define a threshold for the residual signal of 0.0085 . When there are values of the residual signal below the threshold

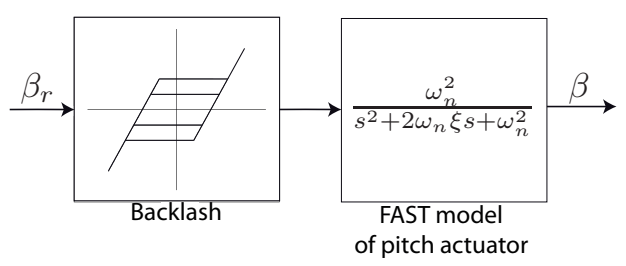

Fig. 4. Pitch fault: backlash 


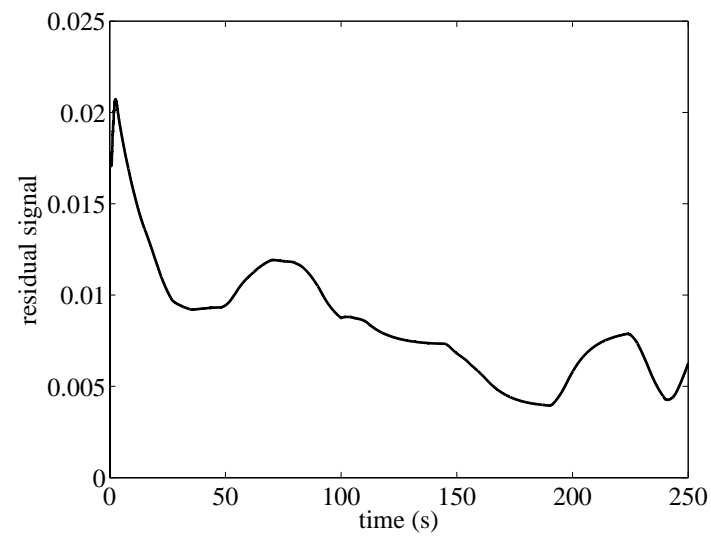

Fig. 5. Plots of $x_{f}(t)$ versus time.

there is a fault in the system. A binary residual signal can be obtained using this idea ( 0 means healthy and 1 means a fault occurred). From 6 it can be seen that there is a delay of approximately 10 seconds to detect the occurring fault.

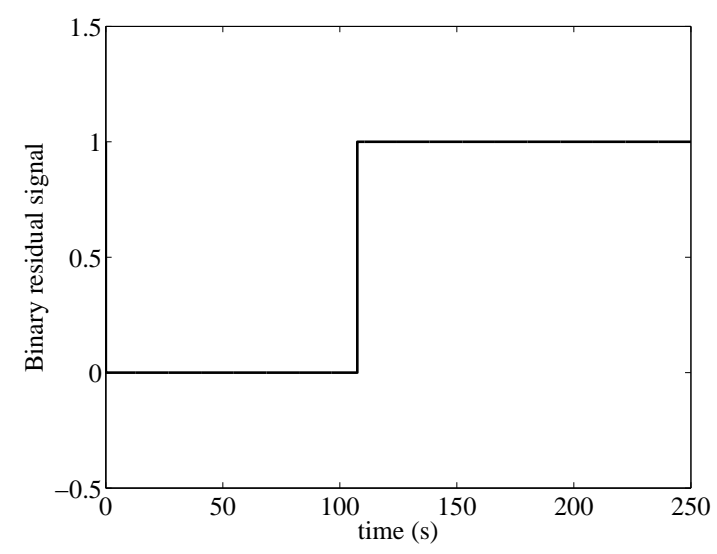

Fig. 6. Binary residual signal.

Figure 7 shows that the rotor speed is near its nominal value of $20 \mathrm{rpm}$ due to the pitch control action.

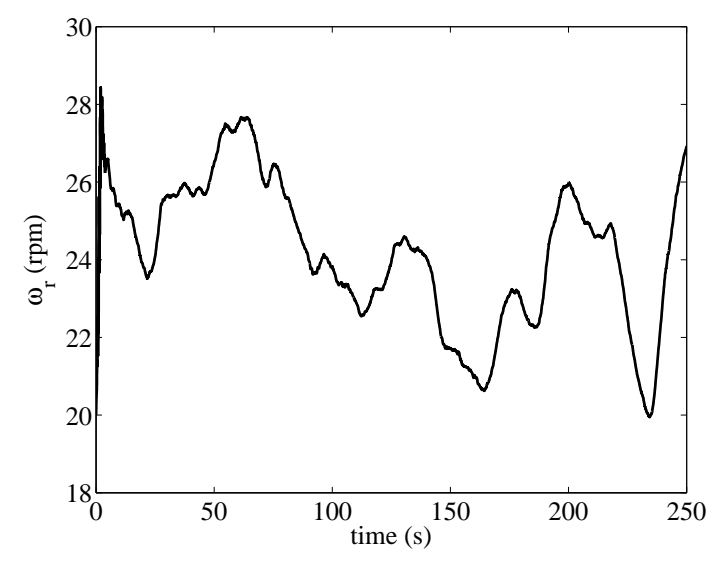

Fig. 7. Rotor speed.

Finally, Figure 8 shows the pitch angle. It is always within the authorized variation domain without exceeding a vari- ation of $10 \%$. From Figure 8 the fault is not self-evident. However, the fault detection system is warning about the occurring fault.

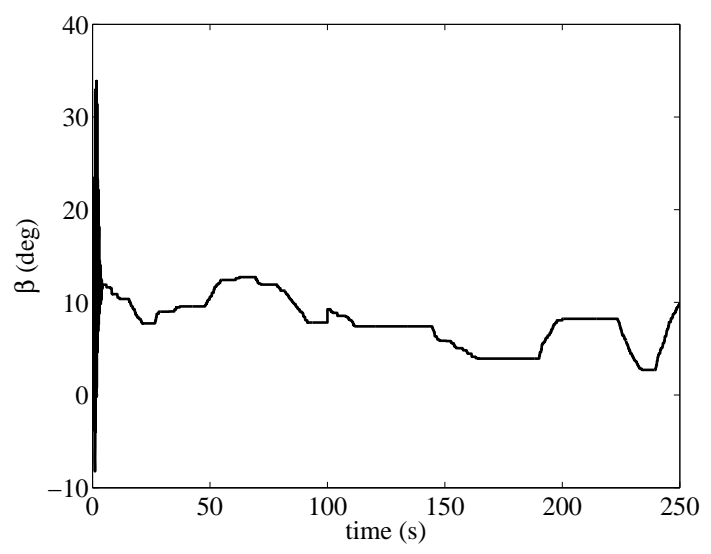

Fig. 8. Pitch control, $\beta$.

Figure 9 shows the torque control magnitude. This torque action is smooth and achieves reasonable values [14].

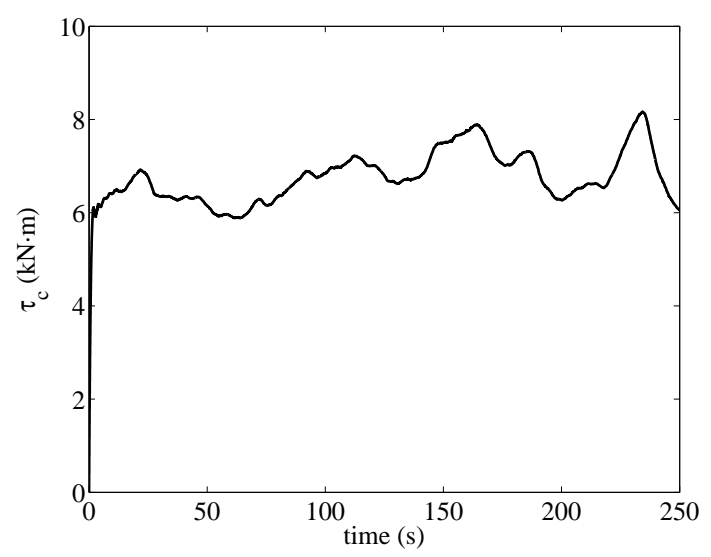

Fig. 9. Torque control.

In Figure 10, the overall fault detection system is sketched in block diagram form.

\section{Conclusions}

Using an alternative WT model and an effective wind speed observer, a pitch fault detection scheme is proposed. The performance has been evaluated using a realistic scenario with the FAST simulator. The fault detection system should be improved in order to be sure that in case of other type of faults it does not give a wrong fault warning.

\section{Acknowledgement}

This work has been partially funded by the European Union (European Regional Development Fund) and the Spanish Ministry of Economy and Competitiveness through the research projects DPI2012-32375/FEDER and DPI201128033-C03-01 and by the Government of Catalonia (Spain) through 2009 SGR 523. 


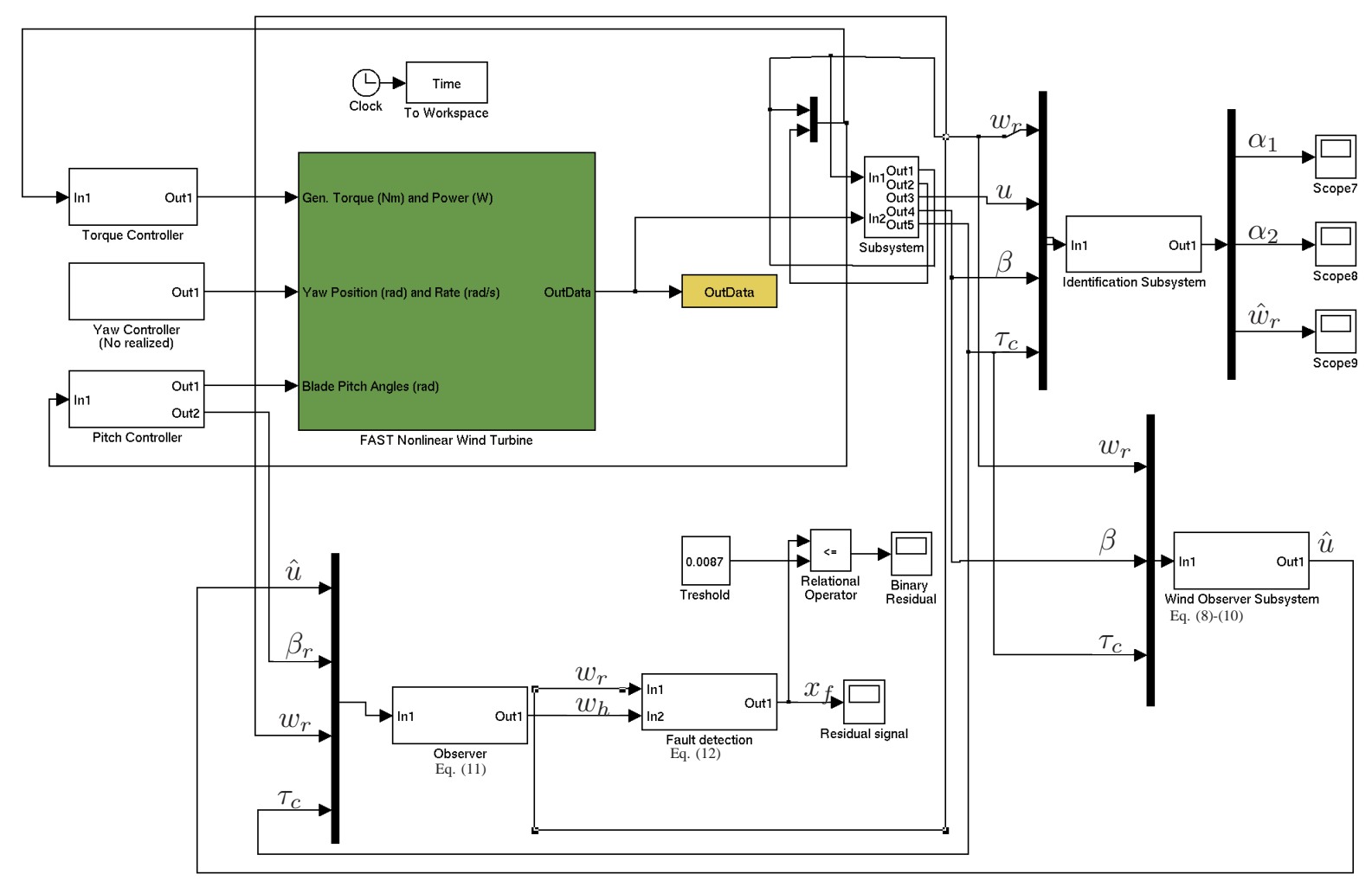

Fig. 10. Block Diagram.

\section{References}

[1] L. Y. Pao, K. E. Johnson, Control of wind turbines: approaches, challenges, and recent developments, IEEE Control Systems Magazine, pp. 44-62, April 2011.

[2] Y. Amirat, M.E.H. Benbouzid, E. Al-Ahmar, B. Bensaker, S. Turri, A brief status on condition monitoring and fault diagnosis in wind energy conversion systems, Renewable and Sustainable Energy Reviews, vol. 13, pp. 2629-2636, June 2009.

[3] Z. Hameed, Y. S. Hong, Y. M. Cho, S. H. Ahn, C. K. Song, Condition monitoring and fault detection of wind turbines and related algorithms: A review, Renewable and Sustainable Energy Reviews, vol. 13, pp. 1-39, June 2009.

[4] P. F. Odgaard, J. Stoustrup, M. Kinnaert, Fault-tolerant control of wind turbines: A benchmark model, IEEE Trans. on Control Systems Technology, vol. 21, pp. 1168-1182, July 2013.

[5] S. M. Tabatabaeipur, P. F. Odgaard, T. Bak, J. Stoustrup, Fault detection of wind turbines with uncertain parameters: A set-membership approach , Energies, vol. 5, pp. 2424-2448, 2012.

[6] K. Z. Ostergaard, P. Brath, J. Stoustrup, Estimation of effective wind speed , J. of Physics: Conference Series, vol. 75, pp. 1-9, 2007.

[7] T. Knudsen, T. Bak, M. Soltani, Prediction models for wind speed at turbine locations in a wind farm, Wind Energy, vol. 14, pp. 877-894, 2011.

[8] R. Ortega, F. Mancilla-David, F. Jaramillo, A globally convergent wind speed estimator for wind turbine systems, Int. J. of Adaptive Control and Signal Processing, vol. 27, pp. 413-425, 2013.

[9] M. N. Soltani, T. Knudsen, M. Svenstrup, R. Wisniewski, P. Brath, R. Ortega, Estimation of rotor effective wind speed: a comparison, IEEE Trans. on Control Systems technology, vol. 21, pp. 1155-1167, 2013.

[10] Z. Xu, Q. Hu, and M. Ehsani, Estimation of Effective Wind Speed for Fixed-Speed Wind Turbines Based on Frequency Domain Data Fusion, IEEE Transactions on Sustainable Energy, vol. 3, no. 1, pp. 57-64, 2012.

[11] H. Camblong, I. M. de Alegria, M. Rodriguez, and G. Abad, Experimental evaluation of wind turbines maximum power point tracking controllers, Energy Convers. Manage., vol. 47, no. 18-19, pp. 28462858, 2006.
[12] R. Cardenas and R. Pena, Sensorless vector control of induction machines for variable-speed wind energy applications, IEEE Trans. Energy Convers., vol. 19, no. 1, pp. 196-205, 2004.

[13] Y. Vidal, L. Acho, F. Pozo, Robust fault detection in hysteretic baseisolation systems, Mechanical Systems and Signal Processing, vol. 29, pp. 447-456, 2012.

[14] Y. Vidal, Acho L., N. Luo, M. Zapateiro, F. Pozo, Power control design for variable-speeed wind turbines, Energies, vol. 5, pp. 30333050, 2012.

[15] Manjock, A. Design Codes FAST and ADAMS for Load Calculations of Onshore Wind Turbines, 2005; National Renewable Energy Laboratory (NREL): Golden, Colorado, USA, 2005.

[16] B. Boukhezzar and H. Siguerdidjane, Nonlinear control of variable speed wind turbines without wind speed measurement, Proceedings of the 44th IEEE Conference on Decision and Control, and the European Control Conference, pp. 3456-3461, Seville, Spain, 2005.

[17] Jonkman, J. NWTC Design Codes (FAST); March 2012; http://wind.nrel.gov/designcodes/simulators/fast/.

[18] Bhat, S.; Bernstein, D. Finite-Time Stability of Homogeneous Systems. In Proceedings of the American Control Conference, Albuquerque, NM, USA, 4-6 June 1997; Volume 4, pp. 2513-2514.

[19] L. Acho, Y. Vidal, F. Pozo, Robust variable speed control of a wind turbine, Int. J. of Innovative Computing, Information and Control, vol. 6, pp. 1925-1934, 2010.

[20] C. C. Fuh, H. H. Tsai, Adaptive paramter identification of servo control systems with noise and high-frequency uncertainties, Mechanical Systems and Signal Processing, vol. 21, pp. 1437-1451, 2007.

[21] M. W. Spong, M. Vidyasagar, Robot dynamics and control, John Wiley and Sons, N.Y., 1989.

[22] N. Khezami, N. B. Braiek, X. Guillaud, Wind turbine power tracking using an improved multimodel quadratic approach, ISA Transactions, vol. 49, pp. 326-334, 2010.

[23] M. Chen, W. H. Chen, Sliding mode control for a class of uncertain nonlinear system based on disturbance observer, Int. J. of Adaptive Control and Signal Processing, vol. 24, pp. 51-64, 2010.

[24] E. A. Bossanyi and P. Jamieson, Blade pitch system modeling for wind turbines. EWEC, Nice, 1999. 